\title{
METHODOLOGICAL ISSUES ON BOTTLED MINERAL WATER RESEARCH
}

\section{Vasiukov O. E., Loboichenko V. M., Sabadash V. V.}

Wide spread of substandard, falsified food products, particularly, bottled mineral water-drinking and mineral packaged water on the Ukrainian market, became the reason for the separation of the identification water examination into a special type of expert activity. This expertise should be considered as a type of comprehensive merchandising and chemical examination, because the object of the study are the marketable characteristics of the production.

The necessity of formation of scientific methodological basis of the identification expertise on the packaged drinking and mineral water, improvement of the ways and methods of its carrying out, particularly, establishing non-compliance with the normative requirements for the water, are caused by the following reasons. Firstly, it's the appearance of a large number of imported packaged drinking and mineral waters on the Ukrainian market, many of which are poorly studied. Secondly, the change in the production technology in many traditional packaged drinking and mineral waters led to the appearance of the water with new consumer properties. And thirdly, it's a wide spread of falsified drinking and mineral packed water on the Ukrainian market, the cost of which is in 500 times higher than the cost of the piped water, and also the imperfection of the normative and legal framework, the lack of the clear mechanism of the water identification and the staff on the necessary level of competence for its realization.

This paper proposes a new indicator for the quality of natural water to establish the fact of non-compliance of bottled drinking and mineral water with normative requirements - identification coefficient as the tangent of the slope angle of the reciprocal conductivity dependence on the degree of the research water dilution with distilled water. An example of the piped water identification among 10 brands of the bottled drinking water is presented.

Keywords: identification expertise of drinking water, conductometric method, identification coefficient, identification criteria.

УДК 343.98:340.67, 54.061

M. В. Зарубіна, старший судовий експерт Харківського НДІСЕ,

I. $\boldsymbol{A}$. Сич, доцент кафедри медичної хімії Національної фармацевтичної академії України, кандидат фармацевтичних наук,

I. B. Cuч, судовий експерт Харківського НДІСЕ

\section{ЕКСПЕРТНЕ ДОСЛІДЖЕННЯ ТРИЦИКЛІЧНИХ АНТИДЕПРЕСАНТІВ}

Розглянуто методи дослідження трициклічних антидепресантів (тіанептину, амітриптиліну, іміпраміну, доксепіну, кломіпраміну). Підібрано найбільи чутливі реактиви, щуо дозволяють диферениіювати та ідентифікувати зазначені лікарські засоби. Проведено їх дослідження методом

(C) Зарубіна М. В., Сич I. А., Сич I. В., 2016 
тонкошарової хроматографії, підібрано системи органічних розчинників $i$ отримано хроматографічні характеристики. Методом ІЧ-спектроскопіі визначено основні смуги поглинання, характерні для лікарських речовин, що досліджувалися.

Ключові слова: трицикличні антидепресанти, тіанептин, амітриптилін, іміпрамін, доксепін, кломіпрамін, якісні реакції, тонкошарова хроматографія, ІЧ-спектрометрія, смуги поглинання.

Перелік лікарських засобів, зловживання якими дедалі частіше відмічається на території України, щороку розширюється та поповнюється новими медикаментами. Так, об'єктами експертних досліджень дедалі частіше стають лікарські засоби групи трициклічних антидепресантів. Це найбільш поширена група антидепресантів, що часто застосовується лікарями для лікування депресивних і панічних розладів.

Антидепресивна активність лікарських засобів цієї групи була виявлена в 1957 р. в іміпраміну, що має у своїй структурі трициклічну систему. Тож, ця група отримала свою назву за спільну їх хімічну будову, а саме системи, що складається 3 двох бензольних кілець зчленованих із центральним семичленним кільцем. Трициклічні антидепресанти хімічно, фармакологічно та токсикологічно дуже схожі на антипсихотики фенотіазинового ряду ${ }^{1}$. Однак поряд із ефективністю в лікуванні депресивних розладів, використання цієї групи медикаментів у дозуванні, що в десятки разів перевищує терапевтичне, може викликати потужний стимулюючий ефект. Серед таких лікарських засобів, поміж наркозалежного населення, застосування знайшов Коаксил (діюча речовина - тіанептин), зловживання яким призводить до тяжких побічних ефектів, ускладнень, лікарської залежності, тяжких токсичних проявів (утрата зору, обширні гангрени при внутрішньовенних ін'єкціях розчину коаксилу) та нерідко летальному кінцю.

Щодо інших представників цієї групи медикаментів, то слід відмітити, що вони дедалі частіше є об'єктами дослідження хіміко-токсикологічних і криміналістичних лабораторій, оскільки їх продаж на території України не $€$ контрольованим, тобто не підлягає предметно-кількісному обліку в мережах аптечних установ. Як наслідок їх неконтрольованого використання гострі отруєння та летальні випадки.

Отже, існує необхідність у створенні чутливих і малозатратних методів дослідження препаратів зазначеної групи для зменшення строків та швидкого реагування при проведенні хімічних і токсикологічних досліджень. 3 цією метою нами були проведені дослідження тіанептину (торговельні назви «Коаксил», «Тіанепит натрію»), амітриптиліну (торговельна назва «Амітриптилін»), іміпраміну (торговельна назва «Меліпрамін»), доксепіну (торговельна назва «Доксепін»), кломіпраміну (торговельні назви «Анафраніл», «Клофраніл»), визначені найбільш чутливі якісні хімічні реакції, підібрані системи для тонкошарової хроматографії, що мають придатні роздільні

1 Див.: Лекарственные средства в психофармакологоии / Ю. И. Губский, В. А. Шаповалова, И. И. Кутько, В. В. Шаповалов ; под ред. Ю. И. Губского. - К. : Здоров'я, 1997. - С. 2. 
характеристики, проведені дослідження методом ІЧ-спектроскопії, що дозволяють ідентифікувати й диференціювати ці лікарські засоби. Нижче наведені основні фізико-хімічні характеристики та структурні формули цих представників зазначеної групи лікарських засобів (рис. 1-5) ${ }^{1}$.<smiles>CN1c2ccccc2C(NCCCCCCC(=O)O)c2ccc(Cl)cc2S1(=O)=O</smiles>

Рис. 1. Структурна формула тіанептину<smiles>CN(C)CCC=C1c2ccccc2CCc2ccccc21</smiles>

Рис. 2. Структурна формула амітриптиліну<smiles>CN(C)CCCN1c2ccccc2CCc2ccc(Cl)cc21</smiles>

Рис. 4. Структурна формула доксепіну<smiles>CN(C)CCCN1c2ccccc2CCc2ccccc21</smiles>

Рис. 3. Структурна формула іміпраміну<smiles>CN(C)CCCN1c2ccccc2CCc2ccc(Cl)cc21</smiles>

Рис. 5. Структурна формула кломіпраміну

1 Див.: Clarke's Analysis of Drugs and Poisons in pharmaceuticals, body fluids and postmortem material / Consulting Editions A. C. Moffat, M. D. Osselton, B. Widdop. Fourth Editions. — C Pharmaceutical Press, 2011. 
За зовнішнім виглядом трициклічні антидепресанти - кристалічний порошок від білого до жовтого кольору, добре розчинний у середньо- та високополярних органічних розчинниках.

На першому етапі дослідження були виділені (екстраговані) тіанептин, амітриптилін, іміпрамін, доксепін, кломіпрамін з відповідних лікарських засобів для отримання чистих зразків діючих речовин. Далі проведені якісні хімічні реакції з використанням найбільш чутливих реактивів, зважаючи на хімічну будову препаратів цієї групи. При цьому використовувалися такі реактиви: ректив Маркі (1 мл формаліну в 9 мл концентрованої сірчаної кислоти), реактив Манделіна (10 мг ванадат амонію у 2 мл концентрованої сірчаної кислоти), Лібермана (1 г нітриту натрію в 10 мл концентрованої сірчаної кислоти), реактив ФПН (5 мл $5 \%$ розчину хлориду заліза, 45 мл $20 \%$ розчину хлорної кислоти, 50 мл $50 \%$ розчину азотної кислоти), реактив Ердмана (20 мл концентрованої сірчаної кислоти, 10 крапель 30 \% розчину азотної кислоти - в 100 мл води) та концентрована сірчана кислота. Використання реактиву Драгендорфа для проведення якісних реакцій у цьому випадку не $\epsilon$ доцільним, оскільки забарвлення лікарських речовин, наркотичних засобів і психотропних речовин з реактивом (коричневе), характерне для всіх лікарських засобів, що містять третинний атом азоту. Отримані результати наведені в табл. 1, 2.

Табличя 1

Забарвлення досліджуваних речовин

\begin{tabular}{|l|c|c|c|}
\hline \multirow{2}{*}{$\begin{array}{c}\text { Зразок } \\
\text { речовини }\end{array}$} & \multicolumn{3}{|c|}{ Забарвлення з використанням основних реактивів } \\
\cline { 2 - 4 } & Маркі & ФПН & $\mathbf{H}_{2} \mathbf{S O}_{4}$ \\
\hline Тіанептин & жовте & - & - \\
\hline Амітриптилін & $\begin{array}{c}\text { коричнево- } \\
\text { помаранчеве }\end{array}$ & - & $\begin{array}{c}\text { помаранчеве, 3 часом } \\
\text { червоно-помаранчеве }\end{array}$ \\
\hline Іміпрамін & - & $\begin{array}{c}\text { блакитне, } \\
\text { засом синє }\end{array}$ & - \\
\hline Доксепін & $\begin{array}{c}\text { червоне, з часом } \\
\text { коричневе }\end{array}$ & - & помаранчеве \\
\hline Кломіпрамін & - & $\begin{array}{c}\text { блакитне, } \\
\text { засом синє }\end{array}$ & - \\
\hline
\end{tabular}

Таблиия 2

Забарвлення досліджуваних речовин

\begin{tabular}{|l|c|c|c|}
\hline \multirow{2}{*}{$\begin{array}{c}\text { Зразок } \\
\text { речовини }\end{array}$} & \multicolumn{3}{|c|}{ Забарвлення з використанням основних реактивів } \\
\cline { 2 - 4 } & Манделіна & Лібермана & Ердмана \\
\hline Тіанептин & фіолетове & оливково-зелене & - \\
\hline Амітриптилін & $\begin{array}{c}\text { коричнево- } \\
\text { помаранчеве }\end{array}$ & коричневе & $\begin{array}{c}\text { жовто- } \\
\text { помаранчеве }\end{array}$ \\
\hline
\end{tabular}


Закінчення табл. 2

\begin{tabular}{|l|c|c|c|}
\hline \multirow{2}{*}{$\begin{array}{c}\text { Зразок } \\
\text { речовини }\end{array}$} & \multicolumn{3}{|c|}{ Забарвлення з використанням основних реактивів } \\
\cline { 2 - 4 } & Манделіна & Лібермана & Ердмана \\
\hline Іміпрамін & блакитне & $\begin{array}{c}\text { блакитне, } \\
\text { з часом синє }\end{array}$ & зелене \\
\hline Доксепін & коричневе & темно-коричневе & коричневе \\
\hline Кломіпрамін & синє & блакитне & зелене \\
\hline
\end{tabular}

Як видно з таблиць, для якісного визначення тіанептину, амітриптиліну, іміпраміну, доксепіну та кломіпраміну реактивами вибору є реактиви Манделіна й Лібермана, які дають можливість диференціювати лікарські речовини одну від одної вже на стадії якісних хімічних реакцій. Однак слід відмітити, що використання зазначених якісних реакцій не є остаточним результатом і для подальшого дослідження необхідне використання інструментальних методів аналізу.

Одним із таких методів $є$ відносно недорогий, але не менш точний метод дослідження - тонкошарова хроматографія. Визначення хроматографічних характеристик проводили в різних системах органічних розчинників. Для тонкошарової хроматографії використовували пластинки Sorbfil. Як реактиви проявників використовувався реактив Драгендорфа та Лібермана. Дослідження проводили в таких системах органічних розчинників: толуол - ацетон - етанол - $25 \%$ розчин аміаку $(9: 9: 1,4: 0,6)$ - система 1 ; етилацетат - метанол - $25 \%$ розчин аміаку $(85: 10: 5)$ - система 2 ; ацетон система 3 ; метанол - аміак $(100: 1,5)$ - система 4. Отримані результати наведені в табл. 3,4 .

Хроматографічна рухливість досліджуваних речовин

Табличя 3

\begin{tabular}{|c|c|c|c|c|}
\hline \multirow{2}{*}{$\begin{array}{c}\text { Зразок } \\
\text { речовини }\end{array}$} & \multicolumn{2}{|c|}{ Значення $R_{f}$} & \multicolumn{2}{|c|}{$\begin{array}{c}\text { Забарвлення зон } \\
\text { хроматографування } 3 \text { реактивами }\end{array}$} \\
\hline & Система 1 & Система 2 & Драгендорфа & Манделіна \\
\hline Тіанептин & 0,04 & 0,05 & коричневе & $\begin{array}{l}\text { коричнево- } \\
\text { жовте }\end{array}$ \\
\hline Амітриптилін & 0,76 & 0,74 & коричневе & коричневе \\
\hline Іміпрамін & 0,63 & 0,64 & коричневе & сине \\
\hline Доксепін & 0,65 & 0,69 & коричневе & чорне \\
\hline Кломіпрамін & 0,73 & 0,73 & коричневе & сине \\
\hline
\end{tabular}


Хроматографічна рухливість досліджуваних речовин

\begin{tabular}{|l|c|c|c|c|}
\hline \multirow{2}{*}{$\begin{array}{c}\text { 3разок } \\
\text { речовини }\end{array}$} & \multicolumn{2}{|c|}{ Значення $\boldsymbol{R}_{f}$} & \multicolumn{2}{c|}{$\begin{array}{c}\text { Забарвлення зон хромато- } \\
\text { графування з реактивами }\end{array}$} \\
\cline { 2 - 5 } & Система 3 & Система 4 & Драгендорфа & Манделіна \\
\hline Тіанептин & 0,26 & 0,88 & коричневе & коричнево-жовте \\
\hline Амітриптилін & 0,34 & 0,73 & коричневе & коричневе \\
\hline Іміпрамін & 0,30 & 0,60 & коричневе & синє \\
\hline Доксепін & 0,31 & 0,64 & коричневе & чорне \\
\hline Кломіпрамін & 0,33 & 0,65 & коричневе & синє \\
\hline
\end{tabular}

Аналізуючи отримані результати хроматографічної рухливості тіанептину, амітриптиліну, іміпраміну, доксепіну, кломіпраміну, наведені у відповідних таблицях, можна зробити висновок про те, що найбільш позитивні роздільні характеристики отримані при використанні системи 3. При цьому величини $R_{f}$ у всіх використаних системах органічних розчинників дуже близькі між собою, тож для підвищення селективності цього методу необхідна обов'язкова наявність зразків зазначених речовин («свідків»).

Крім тонкошарової хроматографії серед інструментальних методів доцільним є використання методу молекулярного спектрального аналізу в ІЧ-ділянках спектру. Однак, як показує експертна практика, на дослідження тіанептин, амітриптилін, іміпрамін, доксепін, кломіпрамін надходять в основному у вигляді пігулок, порошків або розчинів (водних або в суміші зі спиртомісткими сумішами), і поряд з активними речовинами містять наповнювачі або інші компоненти, що використовуються у фармацевтичній промисловості. Зважаючи на це, на відміну від інших інструментальних методів, ІЧ-спектри таких сумішей можуть не давати правильних результатів щодо вмісту активних компонентів. Тож для дослідження зазначеним методом необхідна екстракція (виділення) діючих речовин.

У цьому випадку таблетку (частину таблетки) подрібнювали, гомогенізували, розчиняли в 1-2 мл води, додавали декілька крапель розчину аміаку $25 \%$ до $\mathrm{pH}=7-8$ і 1-2 мл хлороформу. Ретельно збовтували та відбирали нижній хлороформний шар. Його випарювали до отримання сухого залишку. До нього додавали $\mathrm{KBr}$, формували спресовану таблетку за допомогою пресу та досліджували в режимі відбиття світла на ІЧ-Фур'є

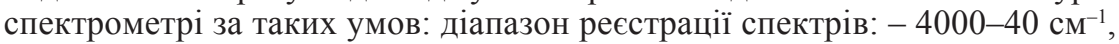
роздільна здатність - 4 см$^{-1}$, кількість сканів - автоматично; швидкість сканування - 1 мм/с, режим сканування - у відбитому світлі; детектор TGS. Під час проведеного дослідження були отримані результати, наведені в табл. 5. 
Таблиия 5

\section{Смуги поглинання досліджуваних речовин}

\begin{tabular}{|l|l|}
\hline \multicolumn{1}{|c|}{ Зразок речовини } & \multicolumn{1}{c|}{ Смуги поглинання з хвильовими числами $\left(\mathbf{c m}^{-\mathbf{1}}\right)$} \\
\hline Тіанептин & $746,769,1280,1294,1347,1710$ \\
\hline Амітриптилін & $757,771,746,969,1015,1258$, \\
\hline Іміпрамін & $741,747,756,767,1230,111$, \\
\hline Доксепін & $750,769,1006,1197,1291,1290$, \\
\hline Кломіпрамін & $755,771,746,965,1014,1257$, \\
\hline
\end{tabular}

Для наочності проведених досліджень з метою встановлення молекулярного складу на рис. 6-9 наведені спектри тіанептину, амітриптиліну, іміпраміну та доксепіну.

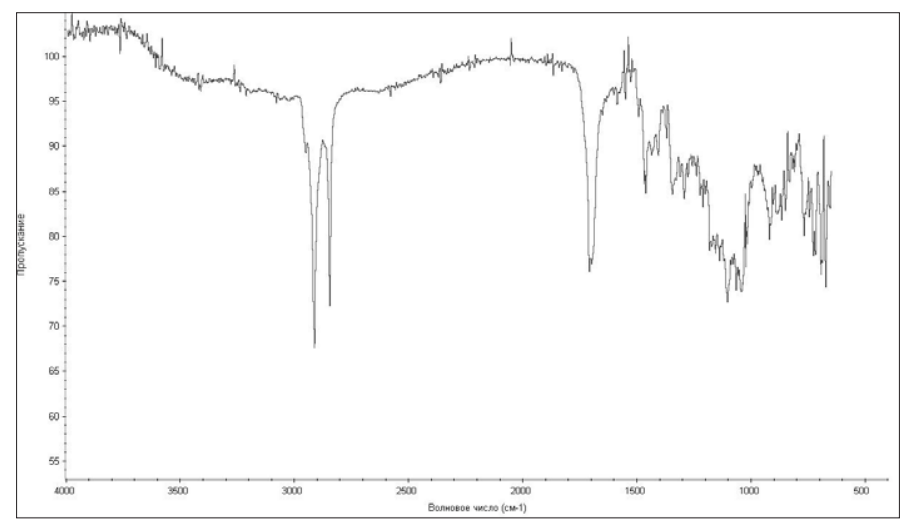

Рис. 6. ІЧ-спектр тіанептину

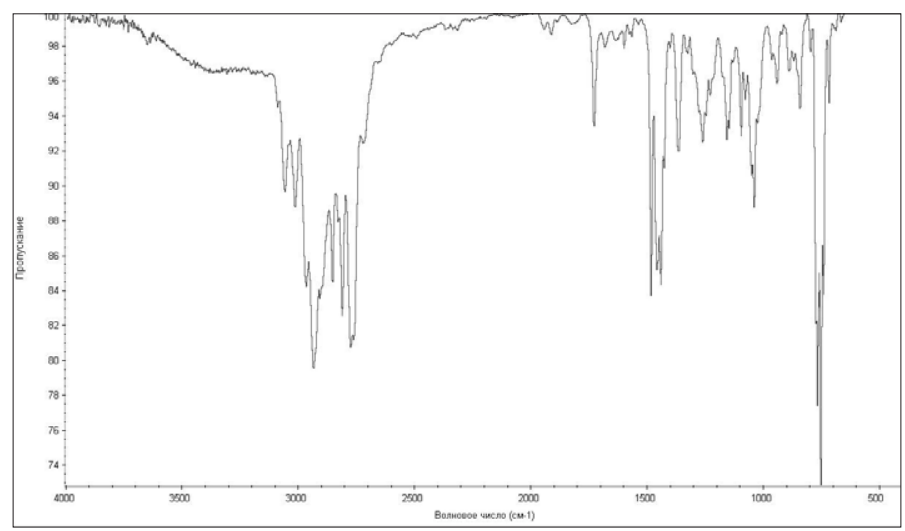

Рис. 7. ІЧ-спектр амітриптиліну 


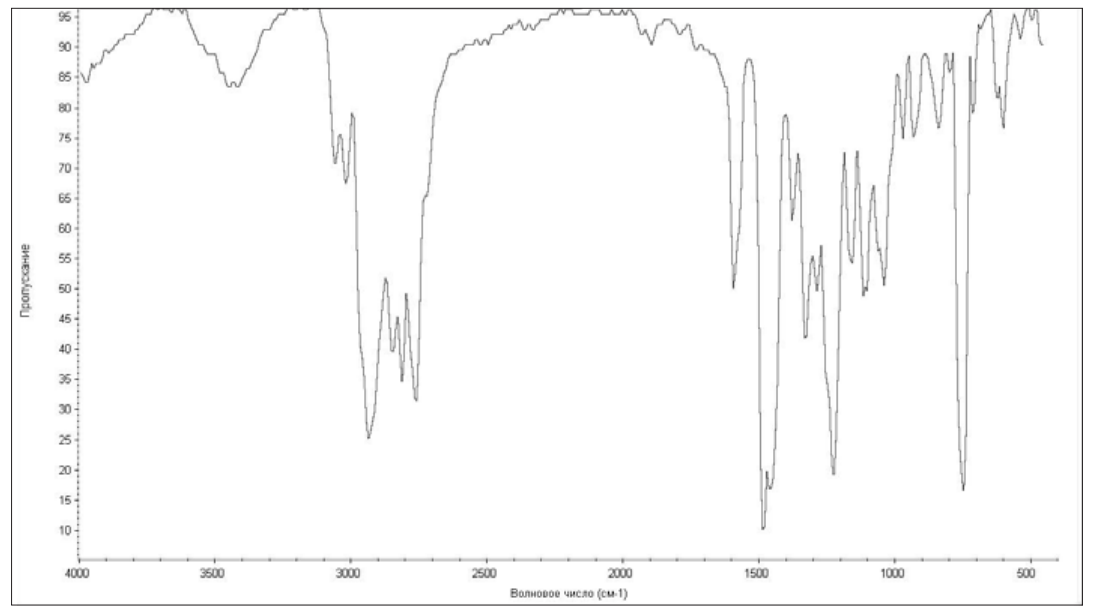

Рис. 8. ІЧ-спектр іміпраміну

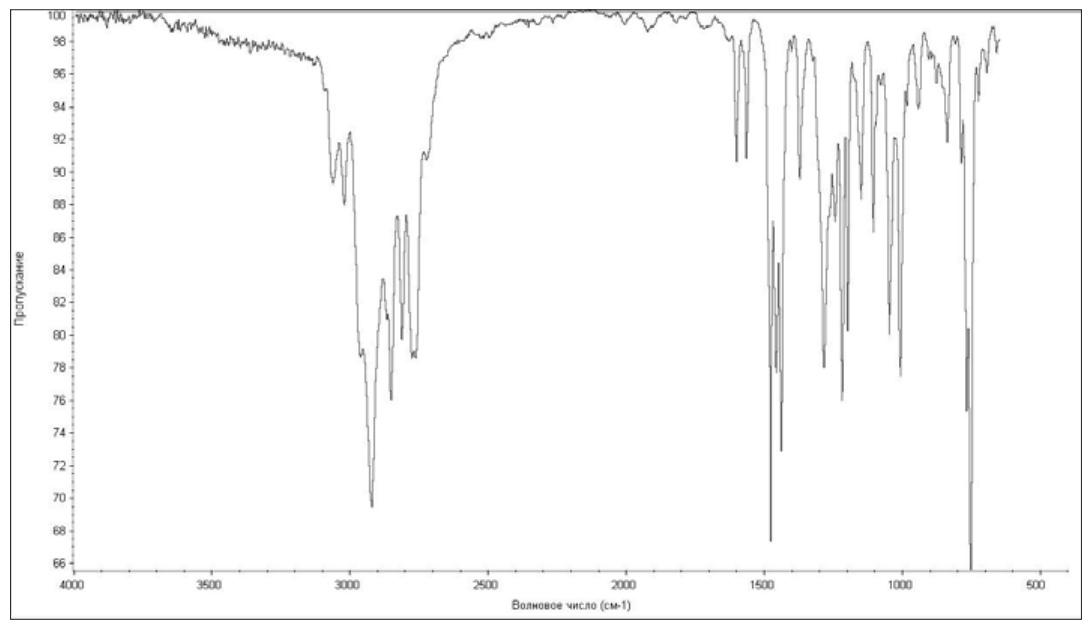

Рис. 9. ІЧ-спектр доксепіну

На основі отриманих експериментальних даних підібрані найбільш селективні якісні хімічні реакції, визначені хроматографічні характеристики та параметри ІЧ-спектроскопії найбільш поширених трициклічних антидепресантів. Комплекс отриманих результатів для якісного визначення лікарських засобів групи трициклічних антидепресантів (тіанептину, амітриптиліну, іміпраміну, доксепіну, кломіпраміну) може використовуватися в експертних установах Міністерства юстиції України, МВС України та хіміко-токсикологічних лабораторіях. 


\title{
ЭКСПЕРТНОЕ ИССЛЕДОВАНИЕ ТРИЦИКЛИЧЕСКИХ АНТИДЕПРЕССАНТОВ
}

\author{
Зарубина М. В., Сыч И.А., Сыч И. В.
}

Рассмотрены методы исследования трициклических антидепрессантов (тианептина, амитриптилина, имипрамина, доксепина, кломипрамина). Подобрань наиболее чувствительные реактивы, позволяющие дифференцировать и идентифицировать эти лечебные средства. Проведено их исследование методом тонкослойной хроматографии, подобраны системы органических растворителей и получены хроматографические характеристики. Методом ИК-спектроскопии определены основные полосы поглощения, характерные для исследуемых лекарственных веществ.

Ключевые слова: трициклические антидепрессанты, тианептин, амитриптилин, доксепин, имипрамин, кломипрамин, качественные реакции, тонкослойная хроматография, ИК-спектрометрия, полосы поглощения.

\section{EXPERT STUDY OF TRICYCLIC ANTIDEPRESSANTS}

\section{Zarubina M. V., Sych I. A., Sych I. V.}

The paper considers the problem of uncontrolled use of tricyclic antidepressant (tianeptine, amitriptyline, doxepin, imipramine, clomipramine) on the territory of Ukraine which are not subjected to subject and quantitative accounting and can be used for nonmedical purposes in doses in ten times exceeding therapeutic. The basic pharmacological properties, physical and chemical characteristics, molecular formulas of substances, trade names of medical products whose active ingredients are tianeptine, amitriptyline, doxepin, imipramine, clomipramine are given. The paper presents an algorithm for detecting said substances with carrying out preliminary sample preparation (extraction) of the medical products. The the methods for qualitative detection of medical products of tricyclic antidepressants group by using the most sensitive and selective qualitative reactions (with reagents of Marki, Lieberman, Erdman, Mandelin), the results of which are shown in the corresponding tables are proposed. Results of research by thin layer chromatography method are interpreted, the systems of organic solvents possessing good dividing properties, corresponding reactants-developers are interpreted up. Chromatographic characteristics of the specified medical substances (size $R_{\rho}$ colouring of zones with various reactants-developers) are defined, results are displayed in corresponding tables. The research results are obtained by using the method of IR-spectroscopy on Fourier IR spectrometer. Characteristic absorption bands of tianeptine, amitriptyline, doxepin, imipramine, clomipramine and their IR spectra are determined. The complex of conducted researches and experimental data can be used in the expert institutions of the Ministry of Justice of Ukraine, Ministry of Internal Affairs of Ukraine, chemical and toxicological laboratories for the qualitative detection of medical products of tricyclic antidepressant group (tianeptine, amitriptyline, doxepin, imipramine, clomipramine) when solving various expert tasks.

Keywords: tricyclic antidepressants, tianeptine, amitriptyline, doxepin, imipramine, clomipramine, qualitative reaction, thin layer chromatography, infrared spectrometry, absorption bands. 